\title{
Participatory Action Research Saved Bullocks of Village Kanadwadi, Maharashtra from Potential Threat of Horn Cancer and Skin Allergy
}

\author{
Bharadwaj S. ${ }^{1}$, Naik K.P. ${ }^{2}$, Chittora R.K. ${ }^{3^{*}}$ and Upreti N.C. ${ }^{4}$ \\ ${ }^{1}$ Senior Community Development Manager, Animal Rahat, Post Box No- 30, Pin Code-416416, Maharashtra, India \\ ${ }^{2}$ Community Facilitator and Animal Rescue Officer, Animal Rahat, Post Box No 30, Pin Code-416416, Maharashtra, India \\ ${ }^{3}$ Senior Veterinary Trainer, Animal Rahat, Post Box No-30 Pin-416416, Maharashtra, India \\ ${ }^{4}$ Chief Operating Officer, Animal Rahat, Post Box No-30 Pin-416416, Maharashtra, India
}

*Corresponding author: rakeshc@animalrahat.com

\begin{abstract}
Kanadwadi, a village situated in district Sangli of Maharashtra, India, where the bullock owners used to get their bullock's horn sheared and painted them using chemical paints and applied chemical colors to the body of bullocks during bail pola festival, which is one of the potential causes of horn cancer and also causes skin allergies. Animal Rahat initiated intervention on this issue and involved this particular village community in the entire process, so as to make the process participatory. All the processes including formulation of the problem/ issue, interpretation of the findings, planning and corrective actions were based on the experiences. This process served community needs and created awareness and commitment to find solution within community. As a result of Participatory Action Research (PAR), villagers agreed not to shear the horns, paint them using harmful paints and application of chemical color on their body, hence saving 30 bullocks of their village and around 200 bullocks of nearby villages from potential threat of horn cancer and skin allergy.
\end{abstract}

Keywords: PAR, Community Participation, Bullocks, Chemical color, Skin allergy, Horn cancer

Bail (bullock) Pola is a festival celebrated widely during monsoon season by farmers of Maharashtra. As per Hindu calendar it is celebrated on the new moon day of Shraavana month; according to Gregorian calendar it comes in month of August or early September. It is a carnival for farmers to offer their deepest gratitude to their bullocks. It is a day when bullocks are worshipped for the contribution they do for their human counterparts. Owner starts preparation of festival 2-3 days in advance. On the day of festival, bullock owner offers their animal special foods, which are traditional Maharashtrian delicacies like Puran poli, Khichadi, and
Bhakri. The food items vary from one village to other. They decorate their bullocks by using many decorative materials, but everything is not a win-win situation for the bullocks. During this festival farmers apply chemical colour on the animal's body and paint their sheared horns using harmful paints. Before applying the harmful lead containing paints, farmer get their bullocks How to cite this article: Bharadwaj, S., Naik, K.P., Chittora, R.K. and
Upreti, N.C. (2020). Participatory Action Research Saved Bullocks of Village
Kanadwadi, Maharashtra from Potential Threat of Horn Cancer and Skin
Allergy. Int. J. Soc. Sci., 9(04): 229-234.
Source of Support: None; Conflict of Interest: None 
horn sheared which is a common practice during this festival. Horn shearing of bullocks is being done by local untrained people and they shear their horns until they become smooth by using sharp objects. Many times while shearing the horn of animals, the blood oozes out of the surface. Due to shearing protective layer of horns is lost and horn's internal layer is exposed to direct sun light comprising of actinic rays, which is one of the potential cause of horn cancer in these animals. Along with shearing, uses of lead containing oil paints on horns have synergistic effect leading to horn cancer. Similarly use of chemical colour on animal's body is also cause of skin allergy. Community led intervention in village Kanadwadi resulted in celebration of Bail Pola festival without use of chemical colour, lead containing oil paints \& horn shearing in the entire village. This village is ten kilometers from the Sangli district headquarter. The population of the village is 1453 and total number of house hold is 319 (source-gram Panchayat). This positive change was not limited to village Kanadwadi but spread to other 5 more neighboring villages in district Sangli of Maharashtra state.

\section{Methodology}

The method adopted for the solution of the identified issue was completely participatory. The issue was identified by Animal Rahat but after 2-3 interactions with the village community; they started to own the process and finally owned the whole process, which was from initial planning to spreading the positive messages. Authors consider this approach as PAR as there are several roots to contemporary application of PAR and each shed light on its unique features. First is the term "action research". This refers to investigations of strategies or principals that can explain or improve a situation. It is linked with evaluation research in its aim to uncover problems or strengths that can be used to better develop an organization or service. It will typically result in "action steps" that are context bound rather than in developing or testing theory that can be generated (Danley et al. 1999).

\section{Background}

A village named Kanadwadi, Taluka Miraj, District
Sangli, Maharashtra, India with 14 bullock owners having 31 bullocks and all the bullock owners have been celebrating Bail Pola festival using chemical colours and harmful paints for decorating their animal specially bullocks. They belong to fair economic group. They love to decorate their animals as they consider it as a religious and traditional practice. Animal Rahat, an animal welfare organisation, provides free treatment services to the bullocks in villages and create awareness amongst their owners for adopting animal welfare friendly management practices.

\section{Entry Point activity}

In 2016, a bullock owner of the village asked Animal Rahat's (AR) veterinarian about problem of Gandhi (Urticaria - red itchy welts that result from a skin reaction) on body of his bullock. AR veterinarian examined the bullock and found that it was an allergic reaction. Veterinarian treated the bullock accordingly and asked owner not to worry. When the bullock owner asked the cause of this problem, then veterinarian explained him that this condition has been caused due to the use of chemical colour on the body of the bullock for decorating on occasion of Bail Pola, but owner was not agreeing with this point as he was applying colour on the body of animals for more than twenty years. AR vet tried to explain to the bullock owner that the urticaria would have been caused this time as he might have used the colours containing high amount of chemicals, but still the bullock owner was not satisfied with the vet's explanation. Team grabbed his resistance as an opportunity for doing a participatory research and asked him to observe his bullock. He agreed and it became an entry point for the further research. Then the facilitators (staff of Animal Rahat) asked the bullock owner to organise a meeting with his friends who want to do this research; and agenda \& venue of the meeting was decided, which was next week.

\section{Meeting, Planning and Execution}

As per plan 5 bullock owners gathered during the decided meeting. As the meeting started, owners were reluctant to accept that use of chemical colours is harmful for their animals. After lot of discussion, three 
of them agreed that they will not use chemical colour on few of their animals and observe, but two of them were not agreeing to this. After long discussion, facilitator also shared his point of view, and he agreed with two owners and explained that it will be better if they both do this next year because now their animals are already applied with chemical colours this year, and the outcome of the research won't be accurate. Finally, they decided to wait until next year. They decided that three among them will not use chemical colour and paints on either animal's body or on their horns respectively. All five of them decided not to shear the horns of their animals too. Hereafter, facilitator met with these owners several times, they met collectively informally. During one of these meetings they wrote all this on a chart paper and decided to not share it with other bullock owners for authenticity of their observations. Facilitator also shared other information with them related to the research topic.

Next year i.e. in 2017, facilitators and five owners who were part of this research started observing the activities of bullock owners prior to day of the Bail Pola festival. After two or three days of festival, they observed that most of the bullocks have developed urticaria on their body (not on all bullocks) and bullocks who haven't developed urticaria, were frequently scratching their body due to itching. But this was not noticed by these bullock owners on their animals. When these five bullock owners who were part of this research discussed with the other bullock owners; they found that others do not consider this as any allergy or disease. This was an issue for the research team because they wanted to save the bullocks from this problem. After two to three months, the bullock owners who were part of the research team discussed with facilitator and tried to find a way out to save the bullocks. AR facilitator agreed and told them that it will be possible only when we all meet and discuss together. On a certain day, they all met and decided few activities. Those activities were:

1. Facilitator will discuss on the points; don't shear horns, use chemical colours and paints with bullock owners every now and then while meeting them.

2. Animal Rahat will display a banner which will depict pictorial message about harmful effects of using chemical colours, paints and horn shearing on the animals.

3. They will organise at least two meetings exclusive for Bail Pola festival i.e. a month before and just few days prior to the next festival.

4. They will manage to announce the preventive messages from the temple loud speaker just before the Bail Pola festival.

5. They will motivate shop owners for not selling chemical colour from at least one month prior to the Bail Pola festival.

Facilitator and the research group decided to make a time line for tracking the types of colour being used during Bail Pola festival and research group also discussed with other bullock owners of village (elders), about how do their grandfathers decorated and coloured their bullocks during the Bail Pola festival in past.

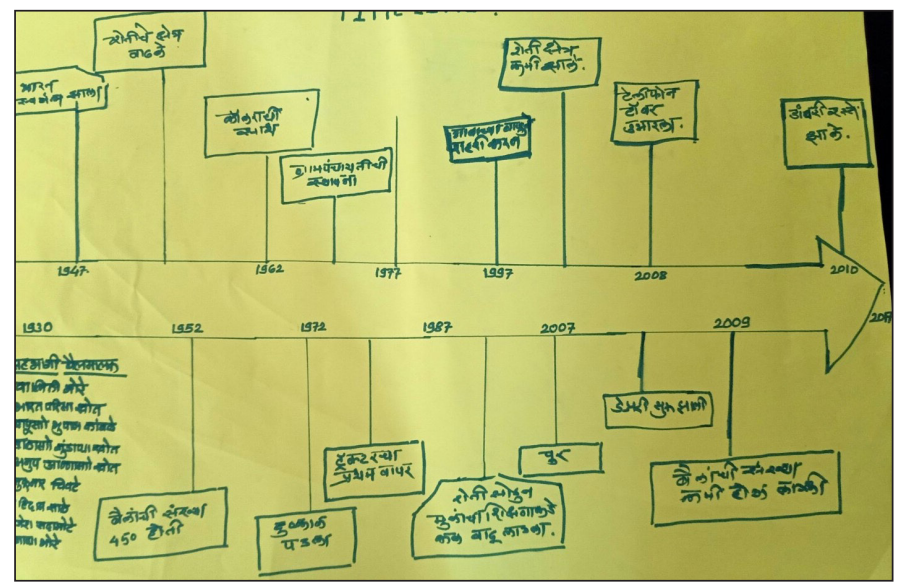

Fig. 1: Time-Line prepared with bullock owners

As a result of this time-line, villagers discovered that chemical colours and paints were not used traditionally, they found out that organic colours like turmeric powder was traditionally used by farmers in past. So by this activity, bullock owners were convinced that use of chemical colours is not in their tradition, but as this festival is for bullocks, they agreed not to use the chemical colour and paints on their bullocks in future. Facilitators provided them option of colouring their bullocks with turmeric powder, wrapping of colourful ribbons around their horns, covering animals body 


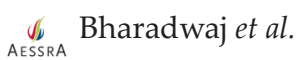
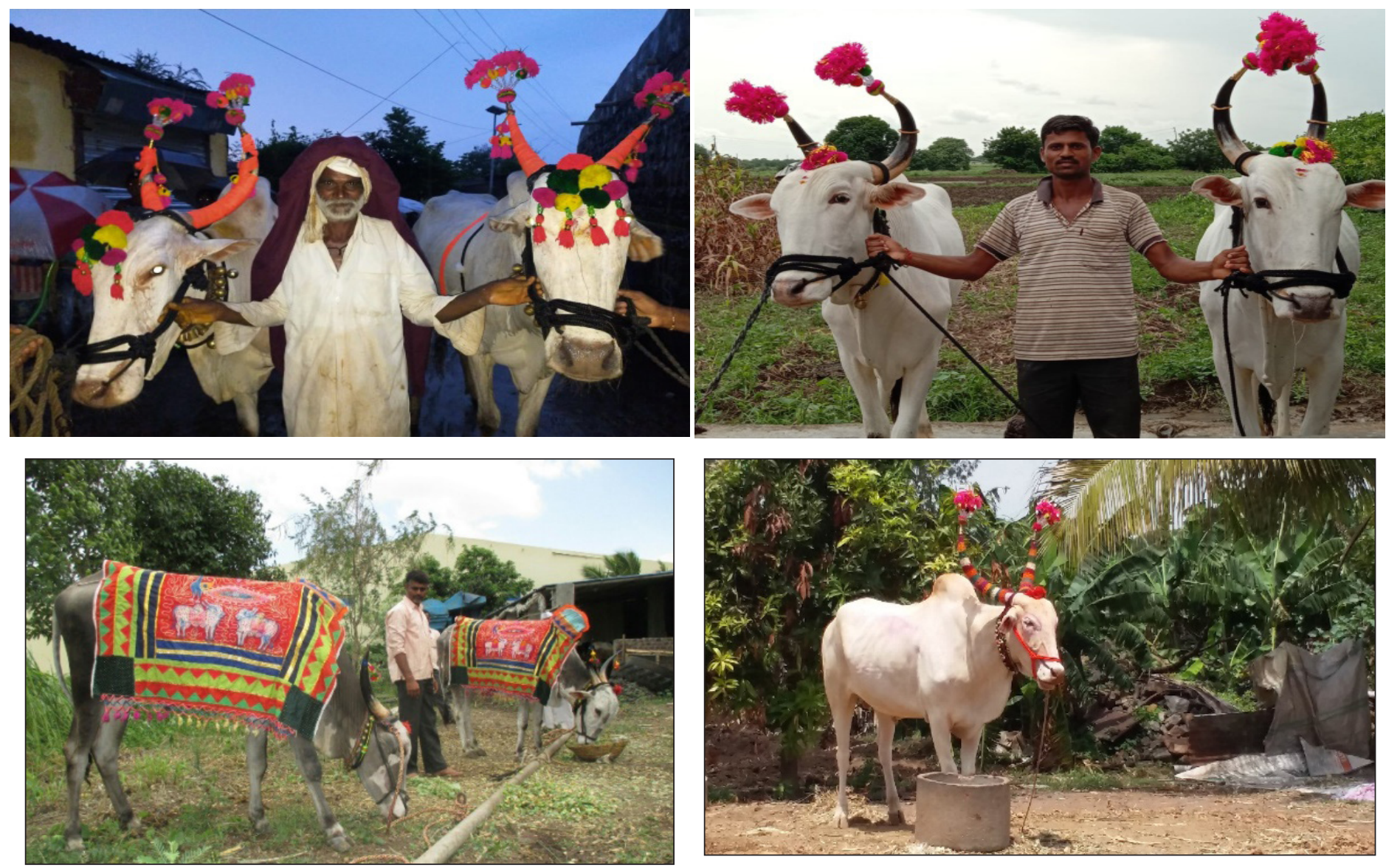

Fig. 2, 3 \& 4: Decoration of bullocks without using chemical colour or painting their horns

with a coloured soft cloth etc. and all these won't cause any harm to animals. Bullock owners whole heartedly agreed for these options and not to use chemical colour, paints and horn shearing during the Bail Pola festival in future.

The dedicated research team of five bullock owners implemented their part and similarly Animal Rahat also implemented activities decided by the research group. Meanwhile facilitator also convinced the Local Health Service Provider (LHP) of that area and urged him to spread the awareness messages in this regard amongst the bullock's owners whenever he gets an opportunity to do so.

Next year in 2018, all bullock owners were convinced and did not use chemical colour and paints on their animals. They also decided that they will never get their bullocks horn sheared, as it is a harmful practise. After getting success in the research process and the execution of its output; they made an informal plan that they will share their observation and findings with bullock owners of nearby villages where Animal Rahat was intervening. Facilitator used them as a resource person while meeting of other villages and saved about two hundred bullocks of 5 villages from the harmful effects of horn shearing, use of chemical colour and paints on the bullocks and other animals. They decided to continue their efforts to maximise their achievement by saving more number of animals from the harmful effects of this practise in future too.

\section{DISCUSSION}

The importance of bullocks in rural life of India is inevitable. Ploughing and tilling of land to a very large extent are still draught animal based even where 
ploughing and tilling operation are carried with tractors, other operations like inter culture and seed drilling are almost exclusively carried out with bullocks (Phaniraja et al. 2009). But at the same time the welfare status of draught animals are not good as draught animal in developing countries, undergo unimaginable suffering in innumerable ways, such as, excessive strain and stress due to overloading, beatings and whip lashes to haul loads beyond their capacity, callosity and neck injury due to defective harnessing, lack of adequate feed and rest (Ramaswamy, 1998).

Bullock owners are habituated to get their bullock's horn sheared, use of chemical colour and paints for decorating them on the occasion of Bail Pola festival, which is quite harmful for animals. Many etiological factors, including constant trauma, actinic rays, varnishes and lead containing paints used in painting the sheared horns to beautify them, hormones, genetic predisposition and viral agents have been suggested as causative factors for horn cancer (Naik et al. 1970). The predisposing factors for occurrence of horn cancer or irritation due to yoke, trauma, tying the rope at the base of the horn, rubbing against hard object, fighting, pairing of horns, painting, solar radiation, genetic predisposition and sex hormone imbalance. Frequent application of paints, varnish, colours, coal tar to beautify them has been suspected to predispose the animals to horn cancer. Apart from potential reason for horn cancer, chemical colour is also potential threat for skin disease (Singh et al. 2006).

Lack of people's involvement has been studied as one of the major cause of the failure of most projects to be implemented effectively. People's participation can make the projects more effective by granting them a say in deciding the objectives and strategies, and by participating in implementation, thereby, ensuring effective utilization of resource. It produces credible and convincing evidence. PAR strengthens knowledge and builds skill that can be used by people experiencing a community problem. The PAR process engages those who are close to the problem (it is "participatory") while also promoting positive change (it involves "action") (Craig Mc Garvey, 2007). The reason to adopt this method was action to improve the situation and research is the conscious effort as a part of the process. It also includes opportunity to formulate knowledge lies in common that adds to theories of action. And ultimately it promotes or inhibit learning in behavioural system. As the issue was initially identified by facilitators, so the proper facilitation plays an important role in mobilizing people which depends more on the behavior, attitudes and commitment of the facilitators who are technology intermediaries, and on who controls the process (Robert Chambers, 2008). Which is also in agreement of this intervention. Communication skill of facilitator is important for constructive switch off the project from organisation to people. Thus, dialog plays important role in PAR. Dialog presents a potent method of integrating inquiry and intervention, and it can contribute to the intermingled process of knowing and changes (Rajesh Tandon, 2008). For facilitator it implies a lifetime of learning, gaining skills and confidence, trying different ways of doing things, searching for alternatives, and adding continuously to the repertoire on which they draw. There are many sources, not least colleagues and co-facilitators (Robert Chambers, 2008).

\section{CONCLUSION}

Combination of community participation in decision making with method of social investigation saved more than two hundred animals of five villages from harmful effect of horn shearing, use of lead containing paints on sheared horn and chemical colors on animal's body.

\section{REFERENCES}

Chambers, R. 2008. Revolutions in Development Inquiry, $1^{\text {st }}$ edition, Earthscan, pp. 133 \& pp. 183.

Craig McGarvey, 2007. Participatory action research involving "all the players" in evaluation and change. This guide is a part of grant craft series; Participatory Action Research.

Danley, K.S. and Ellison, M.L. 1999. A Handbook for Participatory Action Researchers; Implementation Science and Practice, Advances Research Center Publications.

Naik, S.N., Ranuelia, H.P. and Dabholk, R.D. 1970. Carcinoma of the Horn in a Cryptorchid Bull, Path. Vet., 7: 265-269.

Phaniraja, K.L. and Panchasara, H.H. 2009. Indian Draught Animals Power, Veterinary World, 2(10): 404-407.

Ramaswamy, N.S. 1998. Draught Animal Welfare; Applied Animal Behaviour Science, 59(1-3): 73-84. 


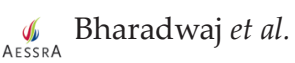

Singh, S.P., Batra, M. and Singh, G.K. 2005. Important aspects of Horn Cancer, The Indian Cow, Oct-Dec, pp. 32-34.

Tandon, R. 2008. Participatory Research Revisiting the roots, $2^{\text {nd }}$ edition, Mosaic Books, pp. 275.
Veena, P., Suresh Kumar, R.V., Sankar, P., Dhanalakshmi, N. and Kokila, S. 2011. Squamous Cell Carcinoma of Horn in a Bullock - A Case Report, Indian Journal of Animal Research, 45: 226- 227. 